\title{
ENERGY MAXIMIZATION AND VOLTAGE REGULATION OF A STAND-ALONE VARIABLE SPEED WIND ENERGY CONVERSION SYSTEM
}

\author{
F. E. Abdel Kader and S. A. Deraz \\ Electrical Engineering Department \\ Faculty of Engineering, Minoufiya University, Egypt
}

\begin{abstract}
This paper presents a new control strategy of a stand-alone wind energy conversion system. The proposed system consists of a tbree pbase induction machine connected to a variable speed wind turbine through a step-up gear box. A current controlled voltage source inverter (CC-VSI) with an electronic load controller (ELC) is connected in parallel with the main load to the AC terminals of the induction machine. The proposed control strategy is based on fuzzy logic control principles which enhance the system performance. There are three fuzzy logic PI controllers and one hysteresis current controller (HCC) which are used to extract the maximum available energy from the wind turbine as well as to regulate the generator terminal voltage simultaneously against wind speed and load variations. A complete mathematical model of the proposed system is developed in order to simulate its performance with the proposed control strategy. Simulation results using Matlab/Simulink demonstrate the effectiveness of the proposed control strategy in capturing the maximum available energy from the wind turbine and in regulation of the generated terminal voltage simultaneously against wind speed and load variations.

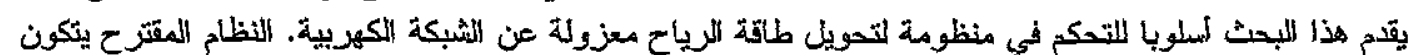

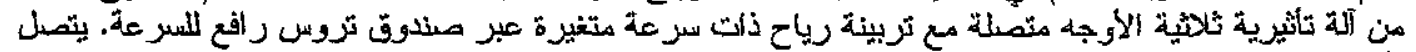

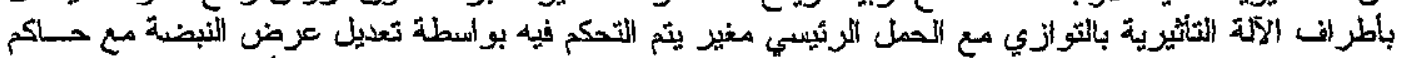

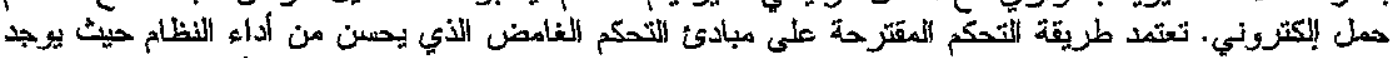

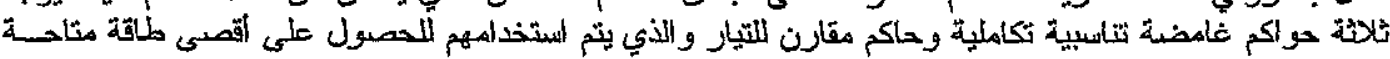

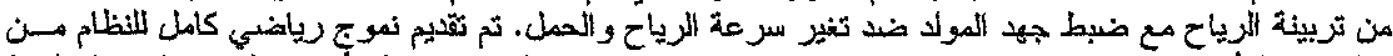

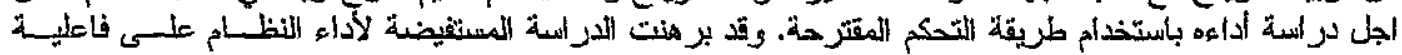

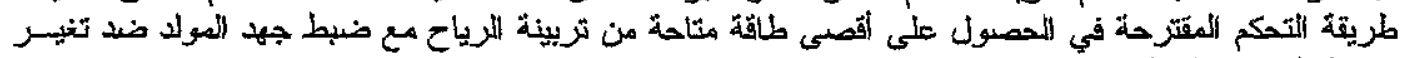

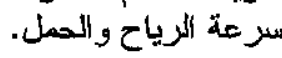

Keywords: Induction generator, Wind turbine, Fuzzy logic control, Electronic load controller, Voltage control, Energy maximization, Modeling.

\section{INTRODUCTYON}

Wind energy is one of the most economical, environmental friendly and promising renewable energy sources. It can be effectively extracted using wind electrical generators. However, in order to have control of the captured energy from the wind turbine, it should operate at variable speed. The main advantages of the variable speed operation of the wind turbine over than the conventional constant speed wind turbine are: the increased energy capture especially at low wind speeds, no-need for the costly blade pitch control mechanism, and the improved dynamic characteristics which result in reducing the mechanical stresses on the shaft and prolonging the life time of the wind turbine [1]. The maximum energy capture is accomplished by controlling the turbine speed (i.e. generator speed) in order to maintain the tip speed ratio at its optimum value and hence to maintain the power coefficient at its maximum value despite wind speed variations. The way in which the turbine speed can be controlled, is by adjusting the loading on the wind turbine. The wind turbine has a unique maximum power point for a particular wind speed, and an attempt to try acquiring more power by deviating from the optimal turbine speed will result in an inefficient transfer of energy from the wind. Nevertheless, control is not always aimed at capturing as much energy as possible. In fact, the captured energy needs to be limited due to mechanical and electrical constraints. Although some specialized machines have shown to be used in electricity generation from the wind, the squirrel-cage induction machines are frequently used as generating units in variable-speed wind energy conversion systems [2-3]. This is due to that, the squirrel-cage induction machines are highly reliable, 
robust, rugged, brush-less rotor construction, need little maintenance, high power density $(\mathrm{W} / \mathrm{Kg})$, have a self protection from severe over loads and short circuits and are very attractive for small and medium power generation systems especially in remote and isolated areas due to their low cost. In order to have the maximum utilization of wind energy conversion system (WECS) which feeds an isolated (or a standalone) load, the WECS itself must regulate the output voltage and the power flow simultaneously. This is a more difficult problem and therefore has attracted little research attention. In [4-5], the variable magnitude variable frequency voltage of the self excited induction generator (SEIG) is first rectified using an uncontrolled rectifier after that the DC link power is transferred to the load through a PWM inverter. By adjusting the modulation index of the PWM inverter, maximum power can be obtained from the wind turbine under wind speed variation regardless the change in the load voltage. In [6], the DC link power is transferred through a buck-type DC/DC converter to supply a battery charging application. By adjusting the duty cycle of the converter, the maximum power can be obtained. Therefore, in order to have control on the voltage and the power flow simultaneously, different techniques using back-to-back PWM converters have been developed [7-11]. The PWM AC-DC-AC interface allows maximum power extraction and at the same time it converts the variable magnitude variable frequency of the generated voltage to constant voltage constant frequency. Such systems can operate in autonomous (stand-alone) or grid-connected applications. However, the main disadvantage of the previous systems arises from the fact that both the two PWM converters have to be rated to at least rated generator power. This increases the costs which makes the stand-alone small-scale wind generation systems find limited applications.

In this paper a new control strategy of a stand-alone VS-WECS is presented. The main objective of the proposed control strategy is to extract maximum available energy from the wind turbine and to regulate the terminal voltage of the induction generator simultaneously against wind speed and load variations. The proposed control strategy uses a single PWM current controlled voltage source inverter (CC-VSI) with an electronic load controller (ELC) on its DC side. The proposed technique reduces the costs of the stand alone wind generation systems which in turn leads to find more applications of such systems in remote and isolated areas.

\section{SYSTEM DESCRIBTION}

Fig. (1) shows the power circuit of the proposed system. The proposed system consists of a threephase induction machine connected to a variable speed wind turbine through a step-up gear box (1:a). A PWM CC-VSI is connected in parallel with the fixed capacitor bank and the consumer load to the AC terminals of the SEIG through a filter reactance. The importance of using the fixed capacitor bank is to eliminate the requirement of pre-charging of the DC side capacitor of the CC-VSI for the start-up process of the induction generator. Moreover, combining the filter inductance and the capacitance of the fixed capacitor bank, a second-order filter is emerged which filters out the high order harmonic components caused by the switching action of the inverter. Since the CC-VSI has no real power source on its DC side, a small real power, which is fed from the SEIG, is required to replenish the internal losses of the inverter and to keep the DC side capacitor charged at a specified level in order to make the inverter able to perform its control action properly.

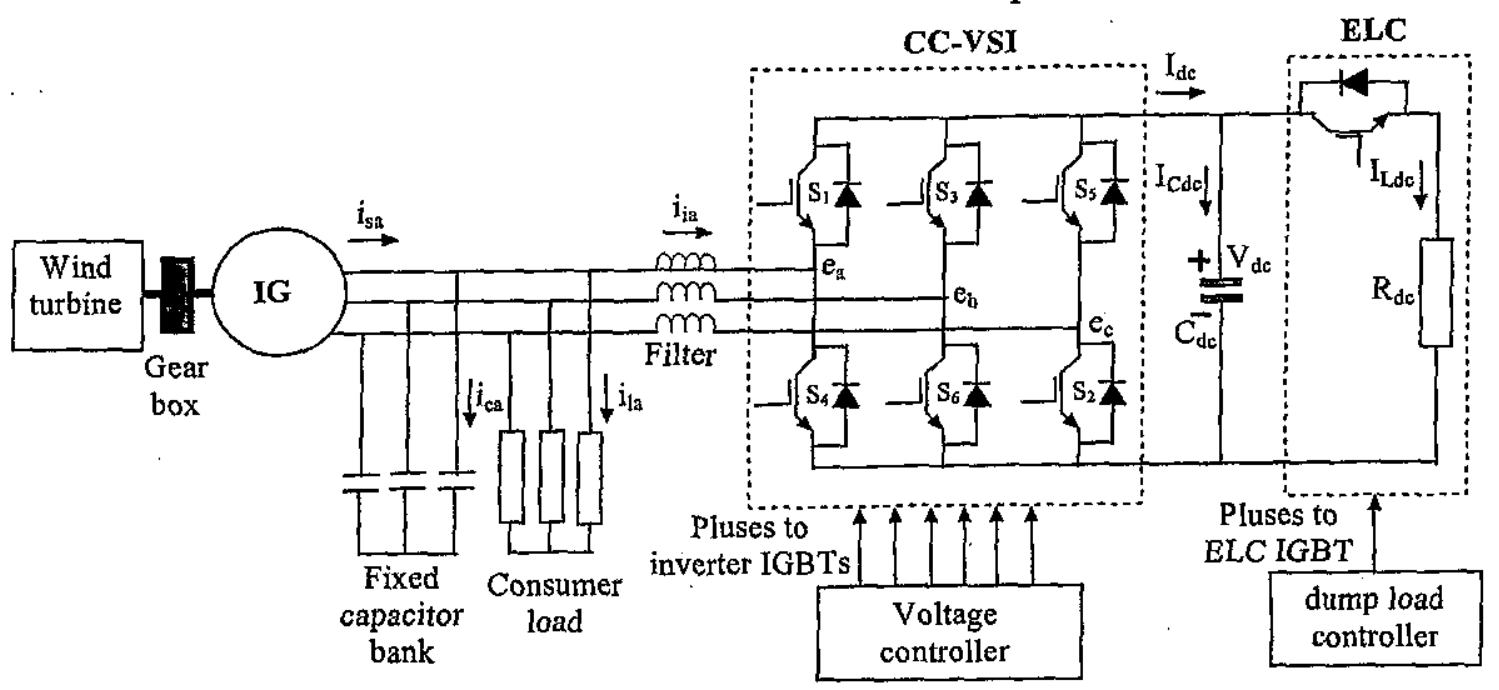

Fig. (1) Power circuit of the proposed system 
In order to have a control on the generator speed to extract the maximum available energy from the wind turbine, an electronic load controller (ELC) is proposed which is connected in parallel on the DC side of the CC-VSI. The ELC consists of an insulated gate bipolar transistor IGBT operating as a chopper connected in series with a dump load. The dump load resistance $R_{d c}$ is designed such that, when the duty cycle of the chopper is unity, it should consume the rated output power of the generator. A freewheeling diode is connected across the dump load for circulating the stored energy in the dump load when the chopper switch is off. The dump load can be a heater load or a battery charging load.

\section{CONTROL STRA'TEGY}

The control philosophy used to regulate the terminal voltage of the SEIG is based on the controlled supply of the output currents of the CC-VSI. As shown in Fig. (2) there are two control loops. The inner control loop forces the actual inverter currents $\mathrm{i}_{\mathrm{i}}(\mathrm{abc})$ to follow the reference currents $i_{i}^{*}(a b c)$ generated by the outer loop through the hysteresis current controller (HCC) which provides the required switching pluses to the inverter. The reference currents $\mathrm{i}_{\mathrm{i}}^{*}$ ( $\mathrm{abc}$ ) are derived by adding two orthogonal current components of each phase. The in-phase active current components $i_{i \alpha}{ }^{*}(a b c)$ (which represent the real power required to replenist the internal losses of the inverter, to supply the dump load and to keep the DC side capacitor charged at a specified level) and the quadrature reactive current components $i_{i \beta}{ }^{*}(a b c)$ (which represent the reactive power required to regulate the generated voltage). Therefore, the AC voltage of the SEIG is sensed and its magnitude is compared with the $\mathrm{AC}$ reference voltage magnitude (which equals to $220 * \sqrt{2} \mathrm{~V}$ ). The $\mathrm{AC}$ voltage error is processed in the first fuzzy logic PI controller (FLC-1). The output of the FLC-1 $\mathrm{i}_{\beta}{ }^{*}$ of the AC voltage control loop is multiplied by the quadrature unit vectors $u_{\beta}(a b c)$ (which lead the unit vectors of $\mathrm{AC}$ voltages by a phase shift of $90^{\circ}$ ) to give the reference reactive current components $i_{i \beta}{ }^{*}(a b c)$ that control the amplitude of the reactive power generated in the CC.VSI. The reference reactive current components lead by a phase shift of $90^{\circ}$ the corresponding $\mathrm{AC}$ voltages for a positive sign of the AC voltage error. While for a negative sign of the $\mathrm{AC}$ voltage error, they lag by a phase shift of $90^{\circ}$. Thus, the CC-VSI operates in capacitive and inductive modes respectively for positive and negative sign of the AC voltage error. Similarly, the in-phase components $i_{i \alpha}$ " (abc) are obtained through the $\mathrm{DC}$ voltage control loop. The $\mathrm{DC}$ voltage error is processed in the second fuzzy PI controller (FLC-2). The output of FLC-2 $i_{\alpha}{ }^{*}$ is multiplied by the unit vectors $\mathfrak{u}_{a}$ (abc) (which in-phase with the corresponding $\mathrm{AC}$ voltages) to give the reference active current components $i_{i \alpha}{ }^{*}(a b c)$. In order to control the electrical loading on the induction generator, an ELC is used. Fig. (3) shows the dump load controller circuit in which the wind velocity is measured using an anemometer. The wind speed signal is used with a pre-determined mathematical equation, which describes the optimal generator speeds for different wind speeds at which maximum available energy is captured, to get the generator speed reference at this particular wind speed. The generator speed reference is compared with the feedback speed and the speed error is processed in the third fuzzy logic PI controller FLC-3. The output of FLC-3 is compared with a saw tooth carrier wave to get the required PWM pulses for the IGBT of the ELC. Fuzzy logic control enhances the system performance due to its non-linear adaptive gains which are varied on-line as the operating point changes.

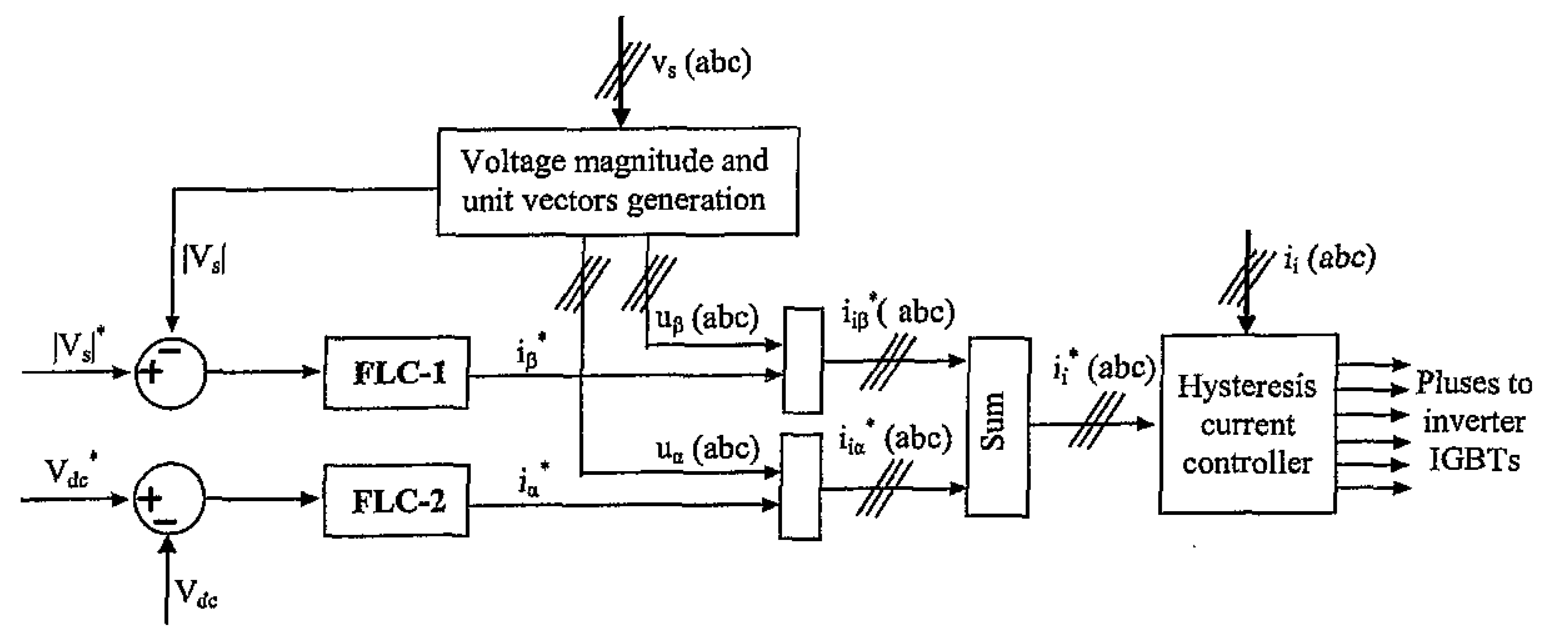

Fig. (2) Voltage controller circuit 


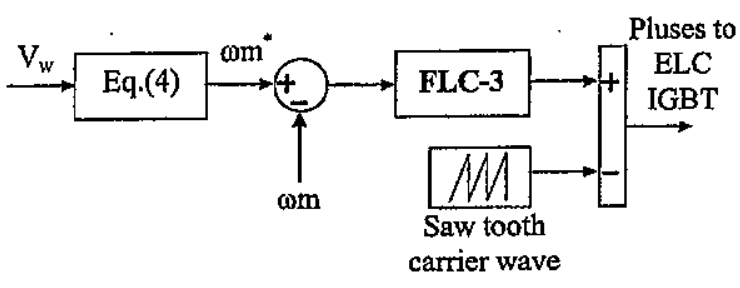

Fig. (3) Dump load controller circuit

\section{SYSTEM MODELING}

\subsection{Modeling Of The Wind Turbine}

The mechanical power $P_{t}$ captured from a wind turbine of a blade radius $x$ running in a wind stream of velocity $V_{w}$ is generally given by [6]:

$$
\mathrm{P}_{\mathrm{t}}=0.5 \rho_{\mathrm{a}} \pi \mathrm{r}^{2} \mathrm{C}_{\mathrm{p}} \mathrm{V}_{\mathrm{w}}^{3}
$$

where $\rho_{a}$ is the air density and $C_{p}$ is known as the power coefficient of the wind turbine which is highly dependent on its constructive characteristics. It is defined as the ratio between the actual power captured to the free stream power flowing through a similar but uninterrupted area and usually represented as a non linear function of the tip speed ratio $\lambda$. The tip speed ratio is the ratio of the linear speed at the tip of the blade to the free stream wind speed and can be given by [6]:

$$
\lambda=\omega_{\mathrm{t}} \mathrm{r} / \mathrm{V}_{\mathrm{w}}
$$

where $\omega_{\mathrm{t}}$ is the angular turbine speed $(\mathrm{rad} / \mathrm{sec})$. A typical relationship between $C_{p}$ and $\lambda$ [7] is shown in Fig. (4). It is clear form the figure that, the parameter $C_{p}$ has a non-linear function with $\lambda$. By using a curve-fitting technique, the parameter $\mathrm{C}_{\mathrm{p}}$ can be mathematically expressed with a polynomial function of seventh degree as a function of $\lambda$ which given as follows:

$C_{p}=a_{7} \lambda^{7}+a_{6} \lambda^{6}+a_{5} \lambda^{5}+\ldots+a_{2} \lambda^{2}+a_{1} \lambda+a_{0}$

where $a_{7}, a_{6}, \ldots, a_{0}$ are constants and are given in the Appendix. Also it can be shown from this figure that, the parameter $C_{p}$ has a unique maximum value $\left(C_{p}=C_{p m a x}\right)$ at the optimum tip speed ratio $\lambda_{\text {opt }}$. Therefore, in order to extract the maximum available power from the wind turbine at any wind velocity, the control system should adjust the turbine speed (i.e. generator speed) in order to force the tip speed ratio $\lambda$ to its optimum value $\lambda_{\text {opt. }}$ Fig. (5) shows the turbine output power characteristics with the generator speed at different wind velocities. The maximum power line is passed through the maximum power points at different wind velocities. The relation between the optimal generator speed with wind velocity can be derived as follows:

$$
\omega_{\mathrm{m}}^{*}=\left(\mathrm{a} \lambda_{\text {opt }} / \mathrm{r}\right) \mathrm{V}_{\mathrm{w}}=244.595 \mathrm{~V}_{\mathrm{w}}
$$

where $a$ is the step-up speed ratio of the gear box, and $\omega_{\mathrm{m}}{ }^{*}$ is the optimal generator speed in rpm.

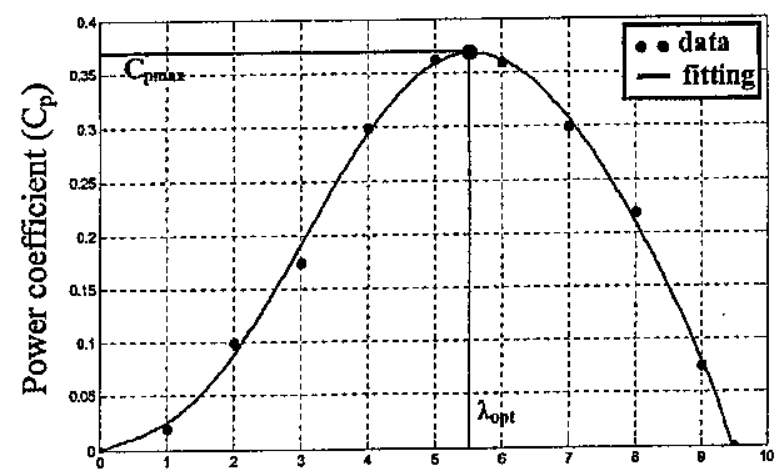

Tip speed ratio $(\lambda)$

Fig. (4) Power coefficient curve

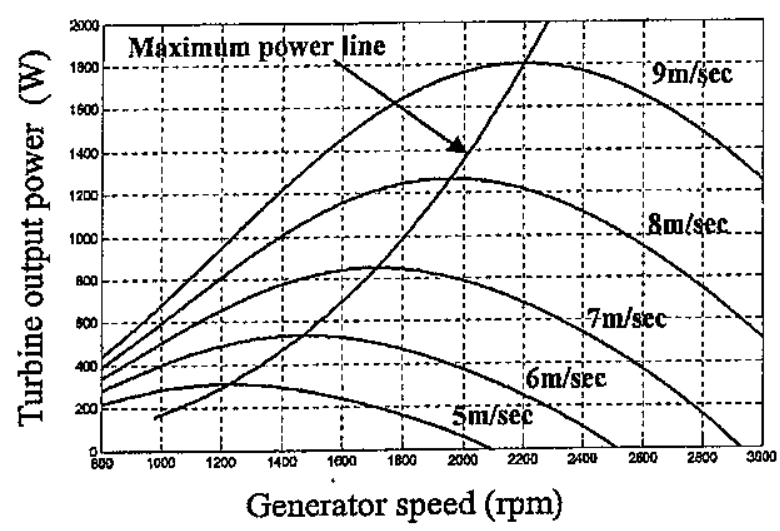

Fig. (5) Turbine output power/speed characteristics

\subsection{Modeling Of The SEIG And The CC-VSI}

The mathematical equations that describe the SEIG model in the d-q stationary reference frame and the CC-VSI are given in [12]. However, these equations can be modified by adding the equations that describe the electronic load controller (ELC). Parameters of the wind turbine and the induction generator are given in the Appendix.

\subsection{Modeling Of The ELC}

The DC side current $I_{d c}$ of the CC-VSI can be expressed as follows:

$\mathrm{I}_{\mathrm{dc}}=\mathrm{I}_{\mathrm{Cdc}}+\mathrm{I}_{\mathrm{Ldc}}$

where $I_{\mathrm{Ldc}}$ is the current passing through the dump load and can be given as follows:

$\mathrm{I}_{\mathrm{Ldc}}=\mathrm{S}\left(\mathrm{V}_{\mathrm{dc}} / \mathrm{R}_{\mathrm{dc}}\right)$

where $S$ is the switching function stating the ON/OFF positions of the ELC IGBT switch and takes a value of 1 and 0 according to the comparison between the output control signal of the FLC-3 and the saw tooth carrier wave. And $\mathrm{I}_{\text {cdo }}$ is the current passing through the DC side capacitor of the CCVSI. The DC voltage equation that describes charging and discharging of the DC side capacitor of the CC-VSI can be rewritten as follows:

$p V_{d c}=I_{c d c} / C_{d c}$ 
where $I_{C d c}$ is the current passing through the DC side capacitor $\mathrm{C}_{\mathrm{dc}}$.

\section{RESULTS AND DISCUSSION}

The proposed system is modeled and simulated using Matiab/Simulink software program in order to study its dynamic performance with the proposed control strategy. In the first, the induction machine is driven by the wind turbine from the rest with a wind velocity of $7 \mathrm{~m} / \mathrm{sec}$. After the speed of the induction machine reaches to its steady state value, the fixed capacitor bank and the inverter are connected across the machine terminals at $t=0 \mathrm{sec}$ in order to excite the induction machine under no-load condition. The fixed capacitor bank is selected with a value of $10 \mu \mathrm{F}$ in order to sustain the generated voltage of the SEIG under no-load condition. Fig. (6) shows the dynamic response of the system during start up process and switching in the voltage controller under no-load condition. Firstly, the terminal voltage of the SEIG settles to $335.72 \mathrm{~V}(\mathrm{RMS})$, whereas the DC side capacitor of the CC-VSI is also charged (due to the anti-parallel diodes across the inverter IGBTs) to $785.02 \mathrm{~V}$ as shown in Fig. (6.a) and Fig. (6.b) respectively. However, the DC voltage does not equal its reference value whish is set to $750 \mathrm{~V}$ and the terminal voltage is over-excited whose reference value is set to $220 \mathrm{~V}(\mathrm{RMS})$. When the voltage controller is brought into operation by giving it a switching pulse at $t=3 \mathrm{sec}$, the over-excited terminal voltage and the DC link voltage are regulated to their reference values by the voltage controller action. In this case, the CC-VSI is operated in inductive-mode where the reactive component of the inverter current lags the voltage of the SEIG by a phase shift of $90^{\circ}$ as shown in Fig. (6.c).

Fig. (6.d) shows the dynamic response of the stator current which is decreased after the controller starts its operation. This is due to that, operation of the inverter in inductive mode reduces the equivalent excitation capacitance of the SEIG which in turn reducing the stator current. Also for this reason, the generator losses are reduced and therefore the extracted power form the wind turbine which equals the generator input power is reduced as shown in Fig. (6.e). This increases the generator speed after switching in the controller as shown in Fig. (6.f). Fig. (6.g) shows the zoomed dynamic response of the actual and reference inverter currents of phase (A). It is clear from the figure that, the HCC forces the actual inverter current to follow its reference in a hysteresis current band. Fig. (6.h) and Fig. (6.i) show the dynamic response of the tip speed ratio and the power coefficient respectively.

Fig. (7) shows the dynamic response of the system under sudden loading with a load resistance $\left(\mathrm{R}_{\mathrm{L}}=\right.$ $300 \Omega$ ) at $t=7 \mathrm{sec}$. In this case, the CC.VSI which is in the inductive mode in the previous case (no-load condition), changes to operate in the capacitive mode in order to inject the required reactive power to regulate the generated voltage as shown in Fig. (7.c). The terminal voltage of the SEIG and the DC side voltage of the CC-VSI are regulated to their reference values after loading condition as shown in Fig. (7.a) and Fig. (7.b) respectively.

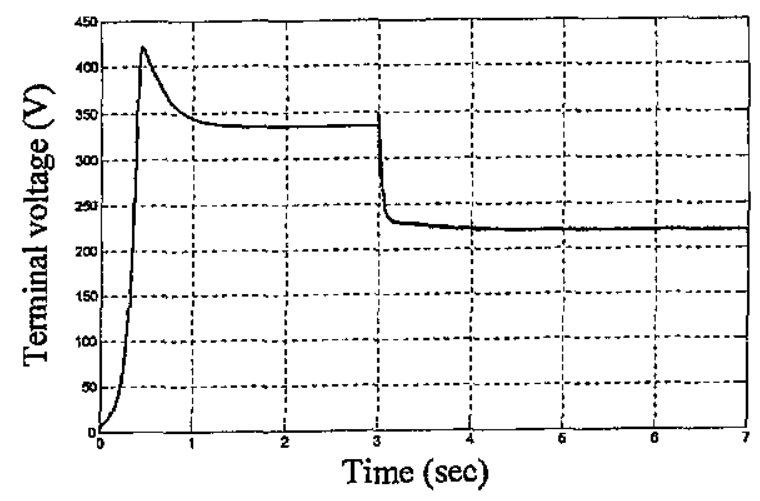

(a) Terminal voltage response

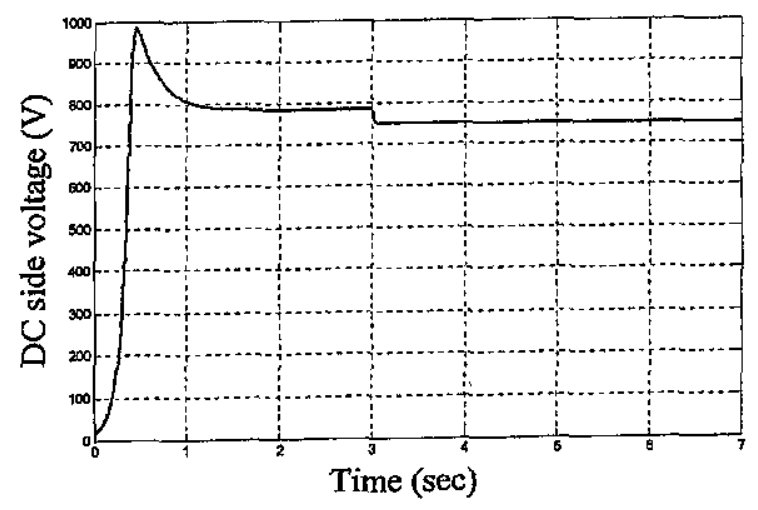

(b) DC side voltage response

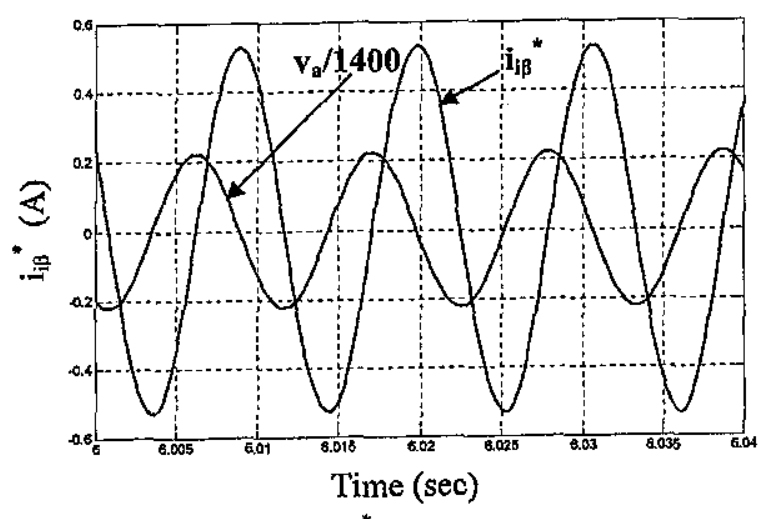

(c) $i_{i \beta}{ }^{*}$ response

Fig. (6) System response during start-up and switching in the voltage controller 


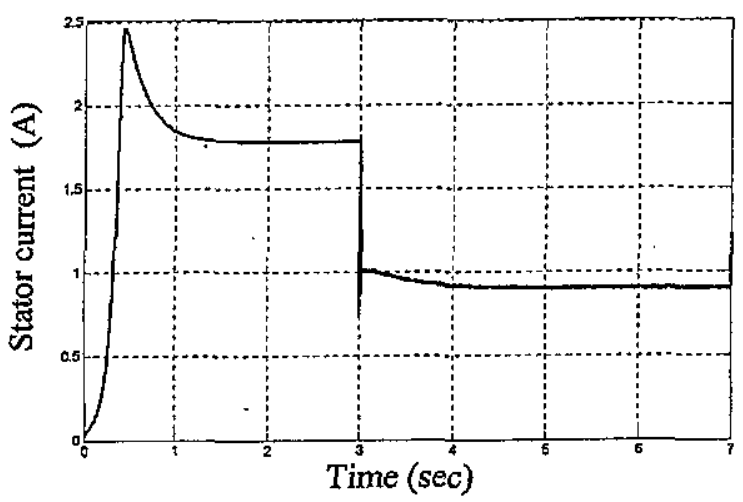

(d) Stator current response

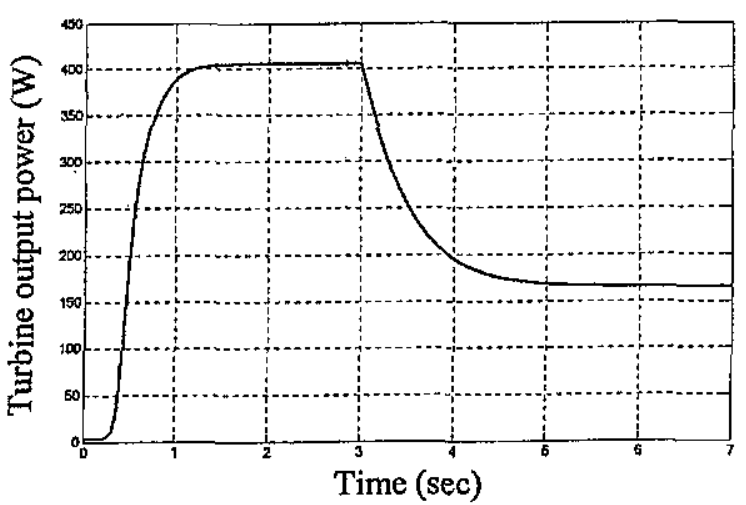

(e) Turbine output power response

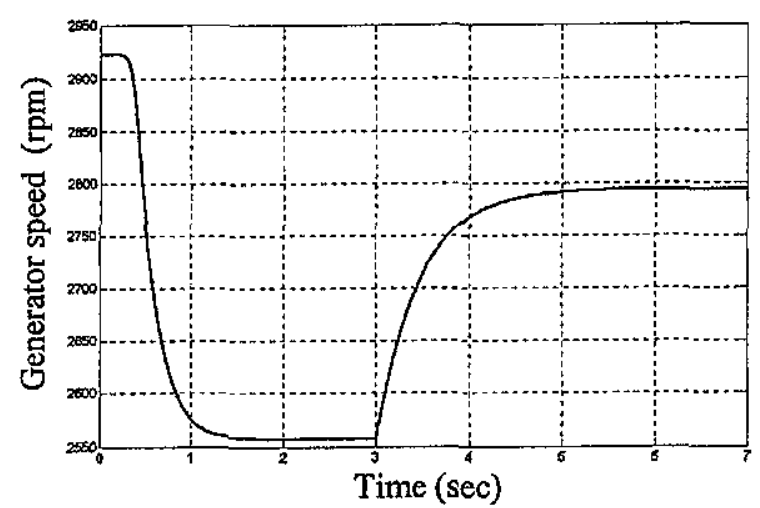

(f) Generator speed response

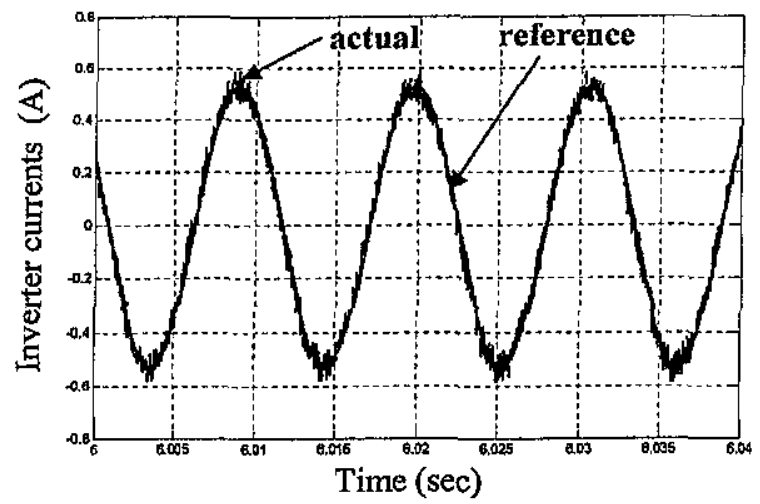

(g) Actual and reference inverter currents response Fig. (6) (continued)

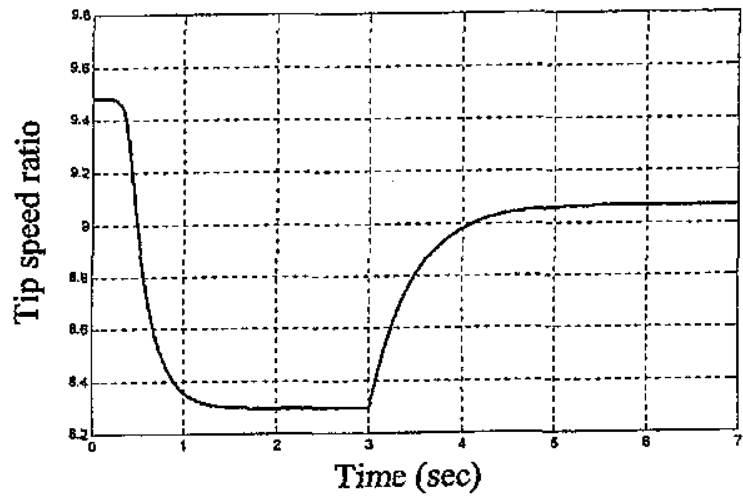

(h) Tip speed ratio response

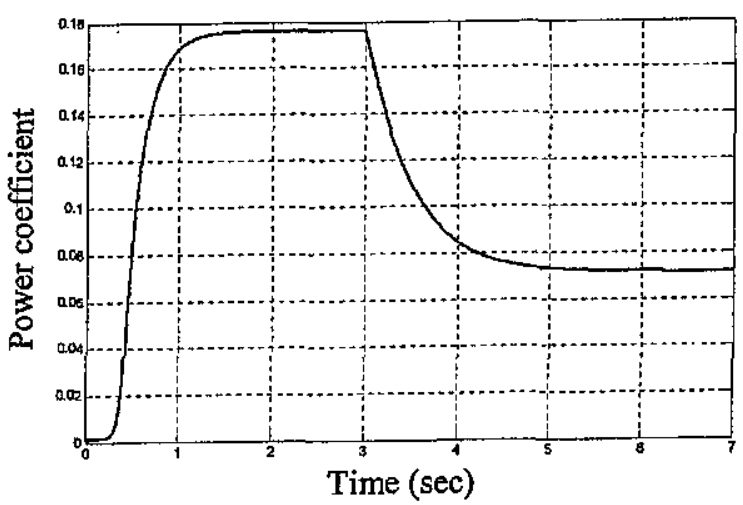

(i) Turbine power coefficient response

Fig. (6) (continued)

In order to study the effect of the dump load controller, it is brought into operation by giving it a switching pulse at $t=16 \mathrm{sec}$. It can be seen from Fig (7), after activation of the dump load controller, the generator speed settles to the optimal reference speed which equals to $1712.17 \mathrm{rpm}$ as shown in Fig. (7.f). Therefore, the available maximum power from the wind turbine is extracted as shown in Fig. (7.e) under constant voltage operation. The excess extracted power over than the extracted power in the previous case is injected in the dump load. The dynamic response of the dump load power is shown in Fig. (7.h).

Fig. (7.i) and Fig. (7.j) show the dymamic response of the tip speed ratio and the turbine power coefficient respectively, which settle to their optimal values by the dump load controller action. The optimal values of the tip speed ratio and power coefficient are given in the Appendix. 


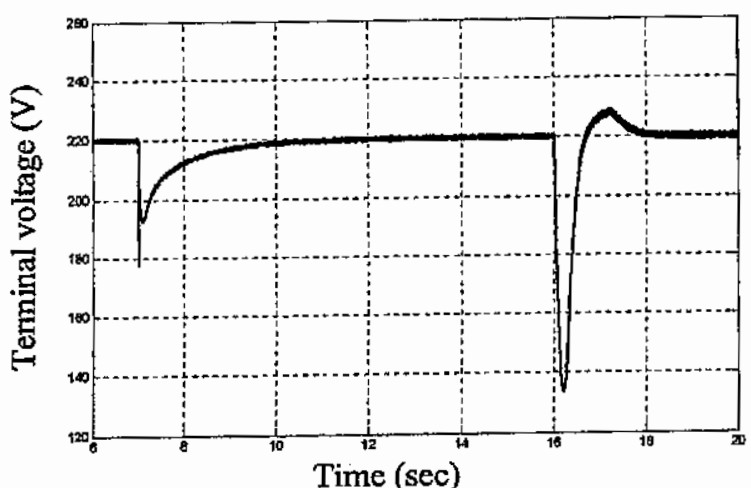

(a) Terminal voltage response

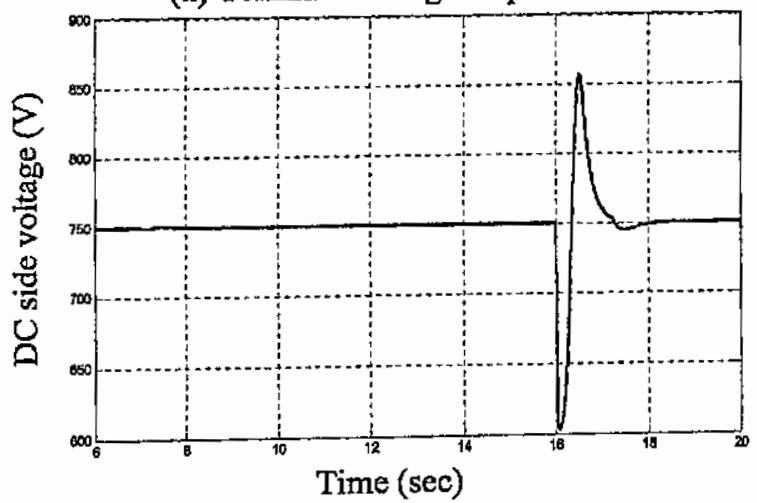

(b) DC side voltage response

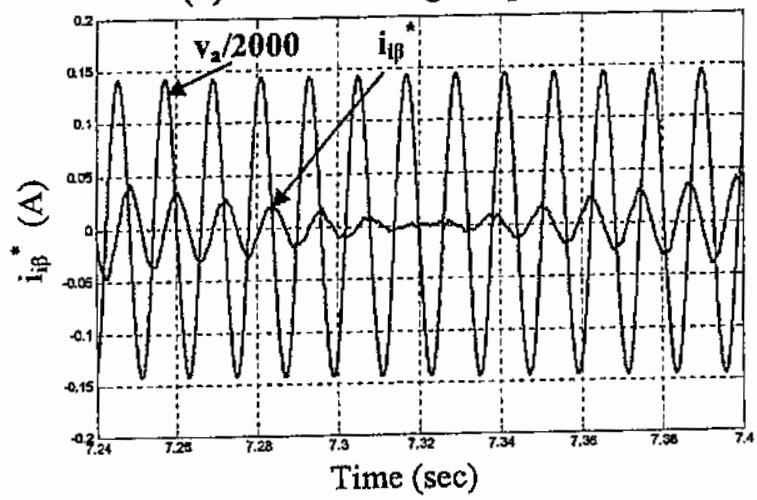

(c) $\mathrm{i}_{\mathrm{i} \beta}{ }^{*}$ response

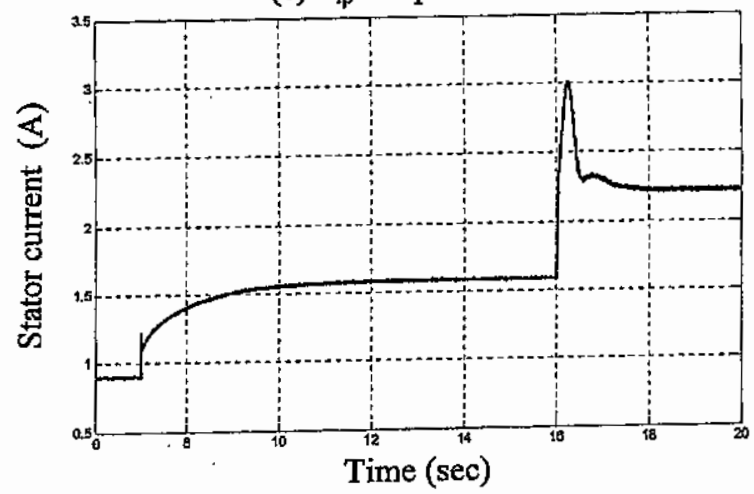

(d) Stator current response

Fig. (7) System response during sudden loading and switching in the dump load controller

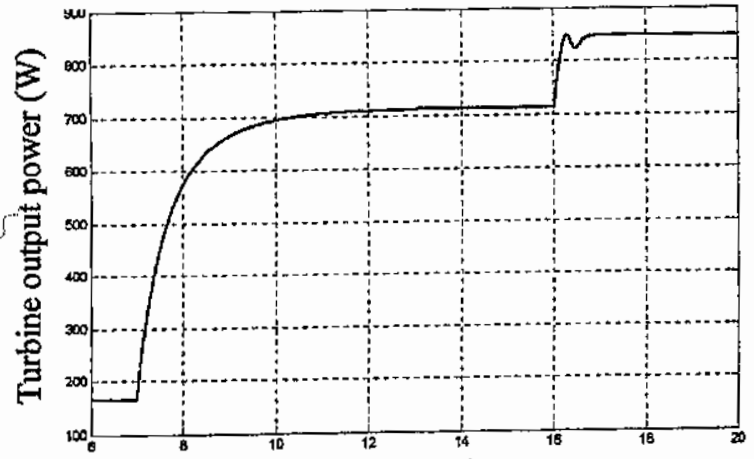

Time (sec)

(e) Turbine output power response

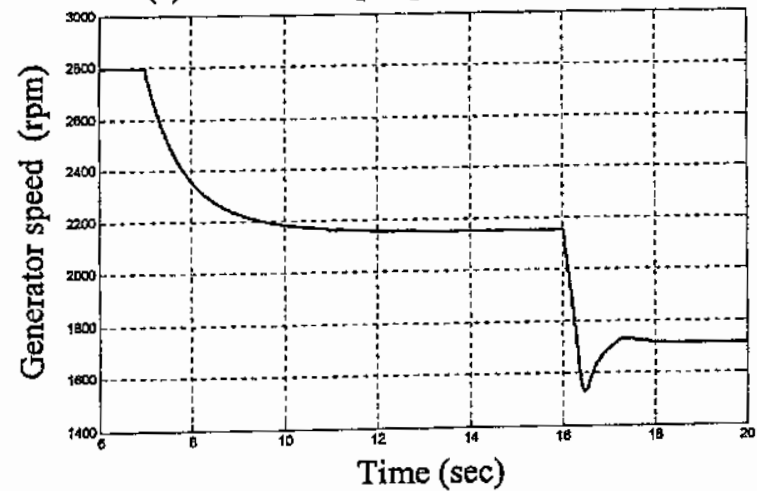

(f) Generator speed response

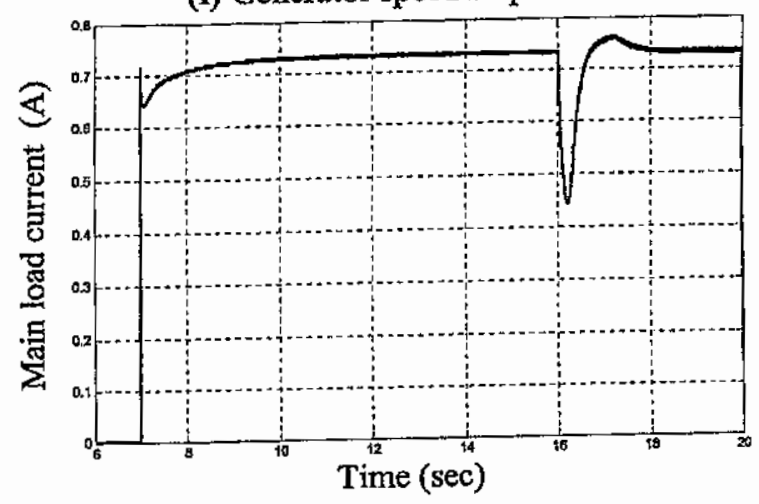

(g) Main load current response

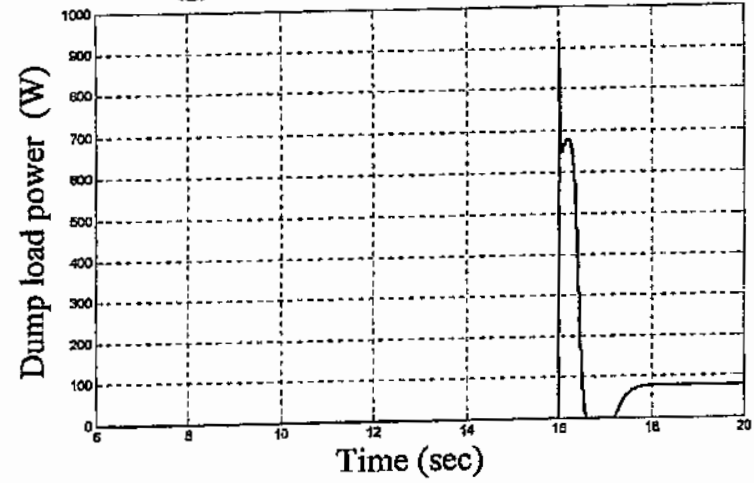

(h) Dump load power response

Fig. (7) (continued) 


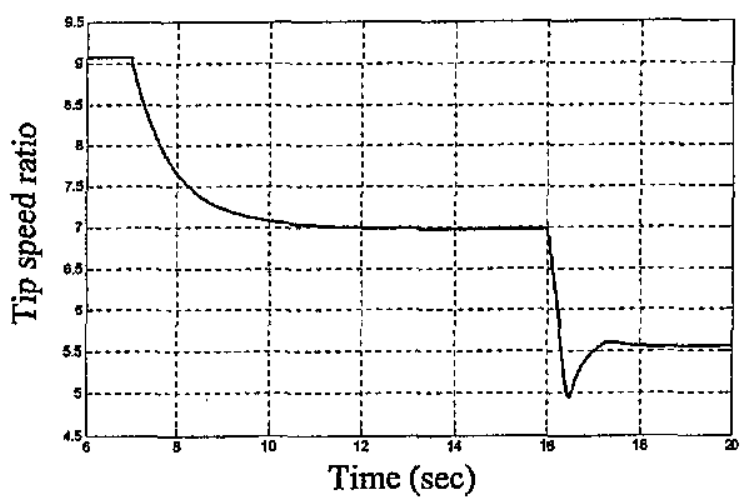

(i) Tip speed ratio response

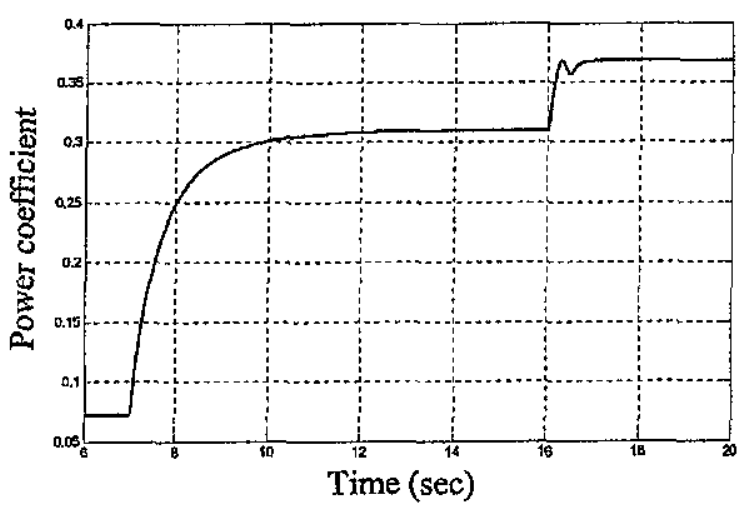

(j) Turbine power coefficient response

Fig. (7) (continued)

Fig. (8) shows the dynamic response of the system under sudden variations in the main load resistance and in the wind speed as shown in Fig. (8.a). The obtained results, which are shown in this figure, demonstrate the effectiveness of the proposed control strategy in capturing the maximum available energy from the wind turbine and in the terminal voltage regulation simultaneously against wind speed and main load resistance variations.

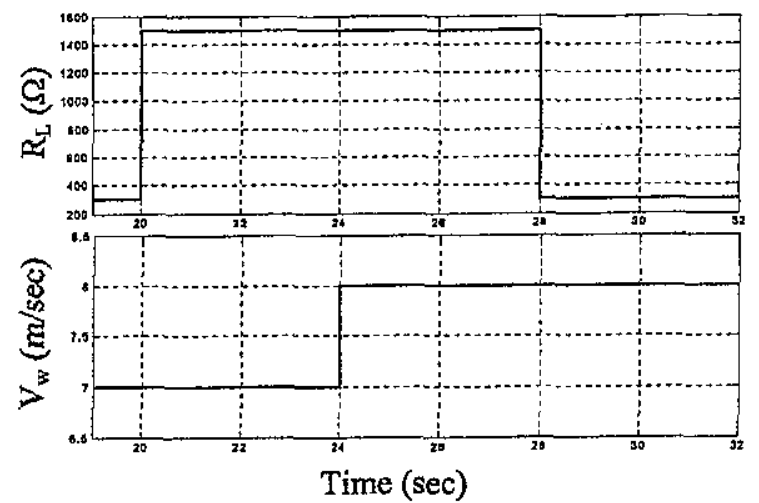

(a) Main load resistance and wind speed variations

Fig. (8) System response under sudden variations in the main load resistance and in the wind speed

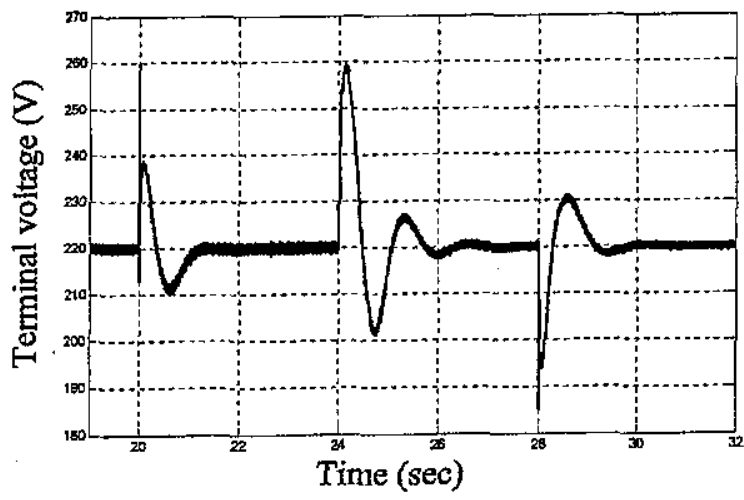

(b) Terminal voltage response

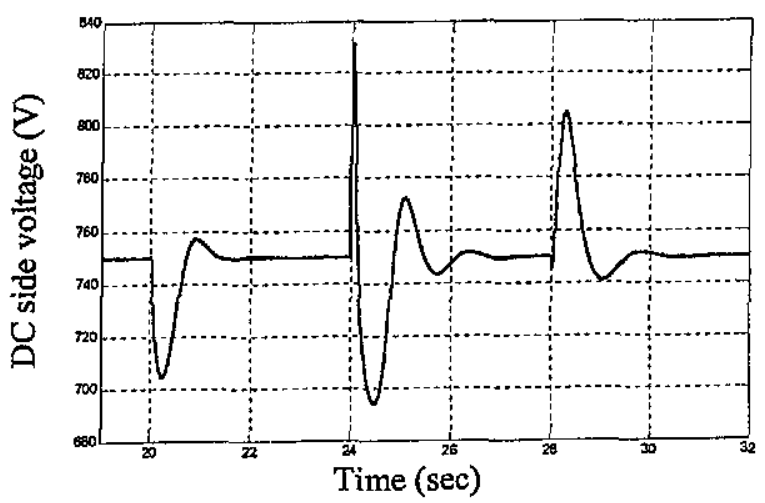

(c) DC side voltage response

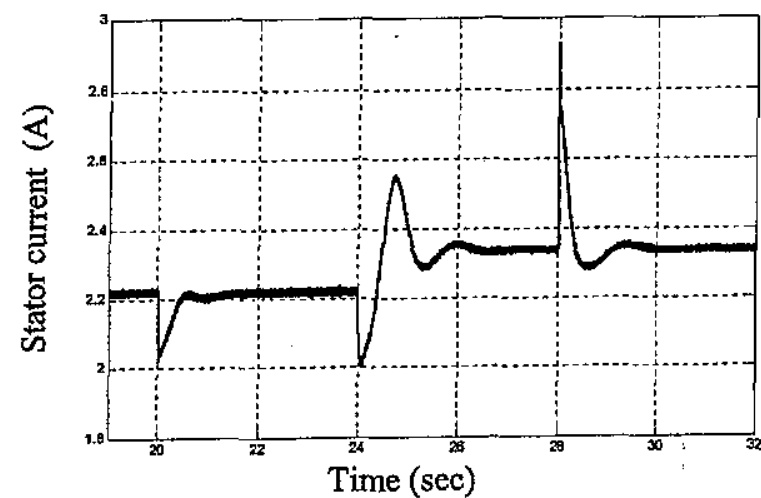

(d) Stator current response

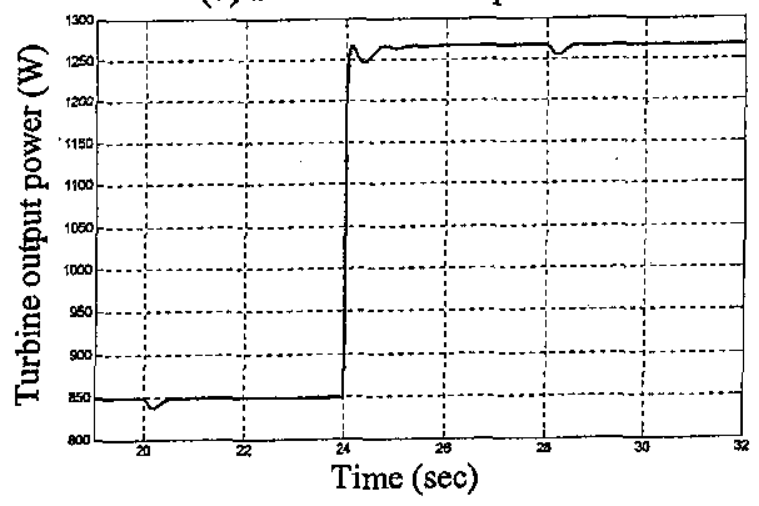

(e) Turbine output power response

Fig. (8) (continued) 


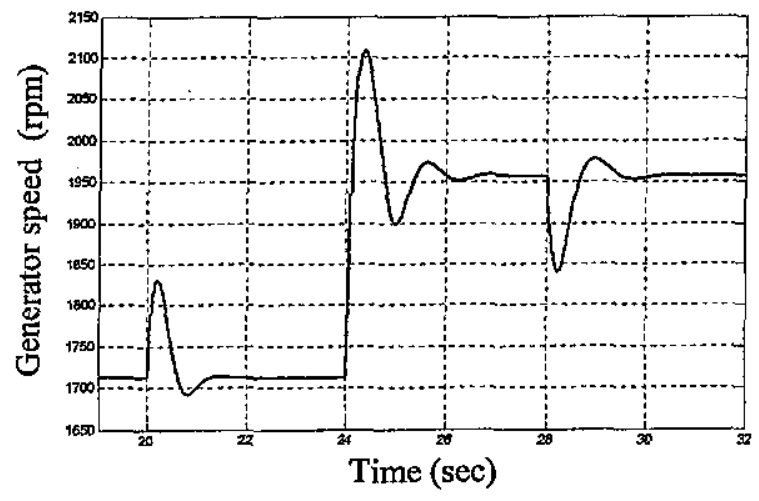

(f) Generator speed response

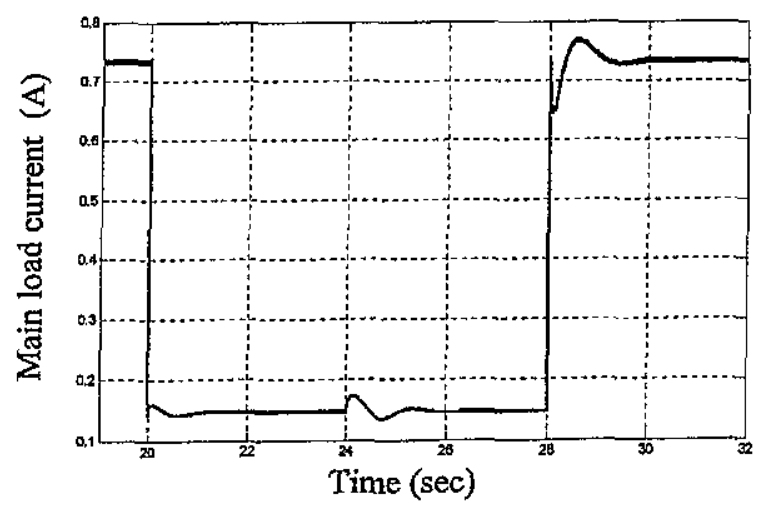

(g) Main load current response

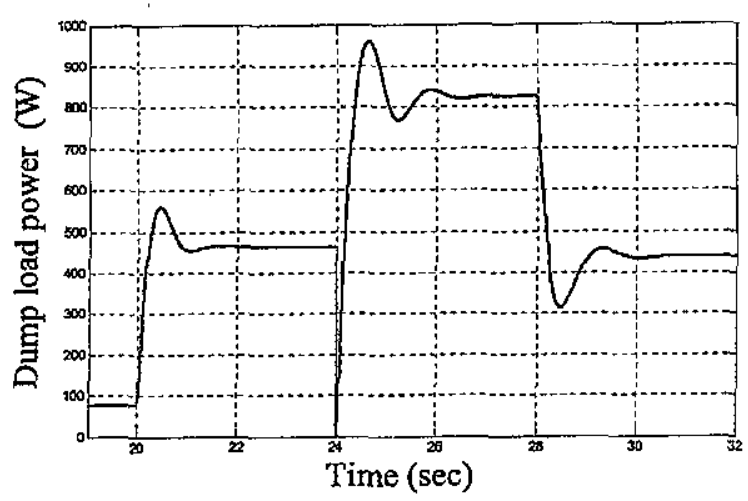

(h) Dump load power response

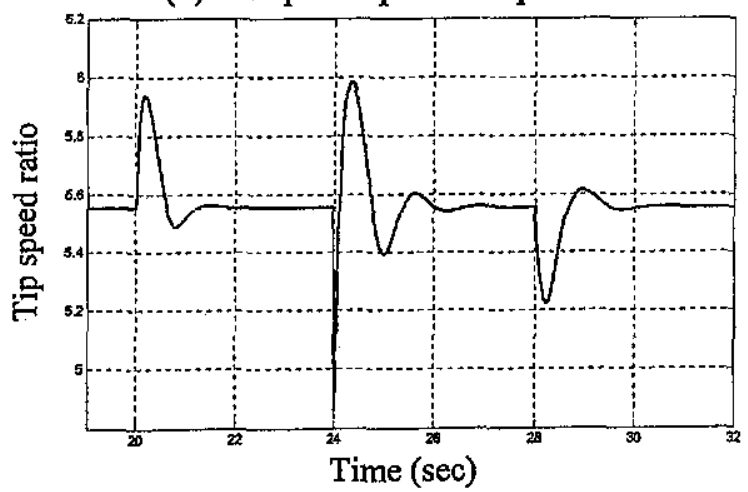

(i) Tip speed ratio response

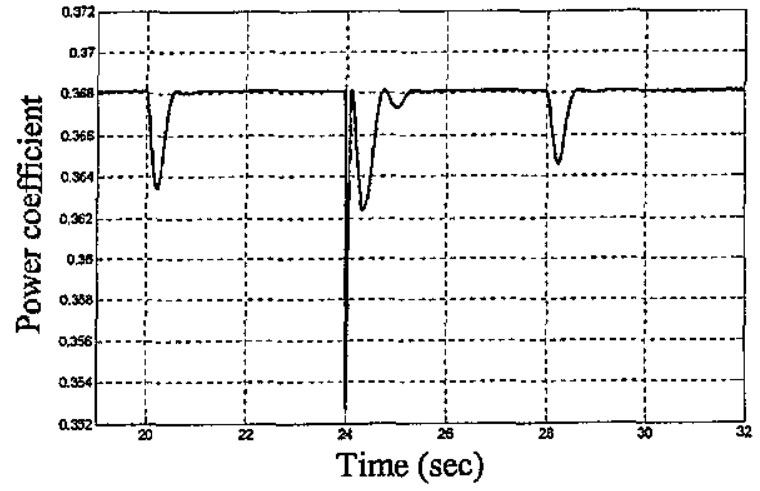

(j) Power coefficient response

Fig. (8) (continued)

\section{CONCLUSION}

A new control strategy of a stand-alone variable speed wind energy conversion system is presented. The control strategy aims to extract the maximum available energy from the wind turbine and at the same time to regulate the generated voltage of the SEIG. The control strategy uses a fixed capacitor bank and a single PWM current controlled voltage source inverter with an electronic load controller on its DC side. Use of a single PWM power converter enables reduced costs of the proposed control scheme which in turn leads to find more applications of wind energy conversion systems in remote and isolated areas. The inclusion of the fixed capacitor bank eliminates the requirement of pre-charging of the DC side capacitor of the inverter for the start-up process of the induction generator and at the time to sustain the generated voltage of the SEIG, this increases the system reliability. The main innovations presented in this work are the modeling of the system and the control strategy which is based on fuzzy logic control principles. Moreover, the proposed control strategy is insensitive to the machine parameters variation. Simulation results using Matlab/Simulink demonstrate the effectiveness of the proposed control strategy in capturing the maximum available energy from the wind turbine and in regulation the generator terminal voltage simultaneously against wind speed and main load variations.

\section{APPENDIX}

-The induction machine used in this study is a 3phase, 4 poles, $1.1 \mathrm{Kw}$. The machine parameters are $R_{s}=6.396 \Omega, R_{r}=7.965 \Omega, L_{l s}=L_{\mathrm{lr}}=20.837 \mathrm{mH}$, $R_{m}=933.61 \Omega, j_{m}=0.015 \mathrm{~kg} \cdot \mathrm{m}^{2}$.

-The wind turbine parameters are: $\mathrm{r}=1.85 \mathrm{~m}$, gear ratio $(1: \mathrm{a})=1: 8.53, \mathrm{j}_{\mathrm{t}}=1.6384 \mathrm{~kg} \cdot \mathrm{m}^{2}$

- $\lambda_{\text {opt }}=5.55501, \mathrm{C}_{\mathrm{pmax}}=0.36805$

-The equivalent system inertia $\mathrm{j}=0.03452 \mathrm{~kg} \cdot \mathrm{m}^{2}$.

Fig. (8) (continued) 
-Constants of Equation (3) are: $a_{7}=4.6324 \mathrm{e}-7, a_{6}=-$ $3.5767 \mathrm{e}-5, \quad a_{5}=8.0176 \mathrm{e}-4, \quad a_{4}=-7.5748 \mathrm{e}-3, \quad a_{3}=$ $0.0289, a_{2}=-0.025952, a_{1}=0.029343, a_{0}=-7.255 e-4$.

\section{REFERENCES}

[1] D. F. Warne, P. G. Calnan, "Generation of electricity from the wind", IEE Proceedings, Vol. 124, No. 11R, pp. 963-985, Nov. 1977.

[2] R. Chaturvedi, S. S. Murthy, "Use of conventional induction motor as a wind driven self excited induction generator for autonomous operation", IEEE Transactions on energy conversion, pp. 2051-2055, Apr. 1989.

[3] S. S. Murthy, B. P. Singh, C. Nagamani, K. V. V. Satyanarayana, "Studies on the use of conventional induction motor as self excited induction generators", IEEE Transactions on energy conversion, Vol. 3, No. 4, pp. 842-848, Dec. 1988.

[4] R. M. Hillowala, A. M. Sharaf, "A rule-based fuzzy logic controller for a PWM inverter in a stand-alone wind energy conversion system", IEEE Transactions on industry applications, vol. 1, pp. 57-65, Jan/Feb 1996.

[5] K. Rajambal, C. Chellamuthu, "Intelligent controllers for an isolated wind energy conversion scheme", Proceedings of IEEE-PEDS conference, pp. 938-943, Apr. 2005.

[6] E. Koutroulis, K. Kalaitzakis, "Design of a maximum power tracking system for windenergy-conversion applications", IEEE Transactions on industrial electronics, Vol. 53, No. 2, pp. 486-494, Apr. 2006.
[7] M. G. Simoes, K. Bose, "Fuzzy logic based intelligent control of a variable speed cage machine wind generation system", IEEE Transactions on power electronics, Vol. 12, No. 1, pp. 87-95, Jan. 1997.

[8] G. Poddar, A. Joseph, A. Unnikrishnan, "Sensorless variable-speed controller for existing fixed-speed wind power generator with unitypower-factor operation", IEEE Transactions on industrial electronics, vol. 50 , No. 5 , pp. $1007-$ 1015, Oct. 2003.

[9] H. G. Kim, D. C. Lee, J. K. Seok, G. M. Lee, "Stand-alone wind power generation system using vector-controlled cage-type induction generators", Proceedings of the ICEMS conference, pp. 289-292, 2003.

[10] R. Pena, R. Cardenas, R. Blasco, G. Asher, J. Clare, "A cage induction generator using back to back PWM converters for variable speed grid connected wind energy system", Proceedings of the IEEE-IECON, pp. 1376-1381, 2001.

[11] Q. Wang, L. Chang, "An independent maximum power extraction strategy for wind energy conversion system", Proceedings of the IEEE canadian conference on electrical and computer engineering, pp. 1142-1147, May 1999.

[12] F. E. Abdel Kader, S. A. Deraz, "Fuzzy logic based voltage control of a self excited induction generator driven by a variable speed wind turbine", submitted to publish in ERJ, Faculty of Engineering, Menoufiya university, Egypt, April 2008. 